\title{
The Effect of Alkyl Chain Length on Well-Defined Fluoro-Arylated Polythiophenes for Temperature-Dependent Morphological Transitions
}

Yuto Ochiai and Tomoya Higashihara*

Cite This: ACS Omega 2020, 5, 33461-33469

Read Online

ABSTRACT: Understanding the relationship between the molecular structure and morphological behaviors of well-defined semiconducting polymers is essential for developing novel conjugated building blocks and determining the origin of the functional characteristics of semiconducting polymers. Here, we provide insights into the significant temperature-dependent morphological transitions of novel well-defined polythiophene derivatives with $m$-alkoxy-substituted fluoro-aryl side units: poly(3(4-fluoro-3-(hexyloxy)phenyl)thiophene) (PHFPT) and poly(3(4-fluoro-3-(dodecyloxy)phenyl)thiophene) (PDFPT). We found that these unique morphological transitions depend on the alkyl chain length of the substituted fluoro-aryl side units. In PHFPT
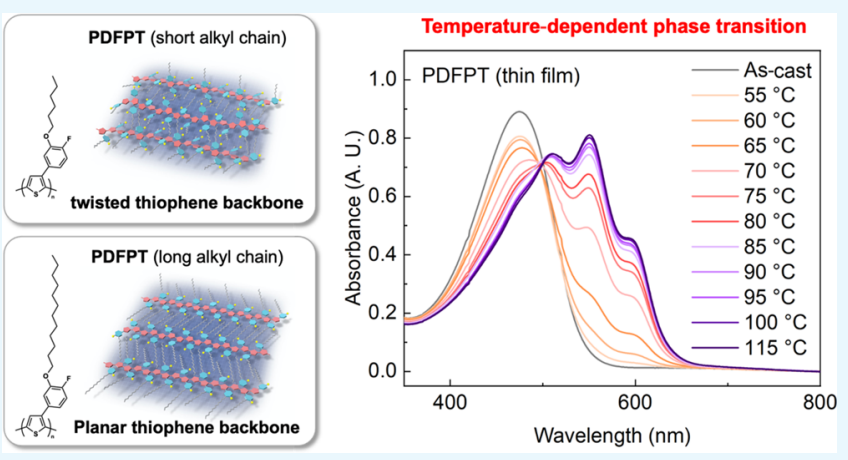
with short alkyl chains, the thermal treatment promotes a crowded interdigitated packing structure, resulting in narrow lamellar spacings in its crystalline structure. In contrast, the long alkyl chain of PDFPT acts as a physical spacer and disturbs the crowded interdigitation. In addition, the thermal treatment induces the backbone planarization and an ordered packing morphology in PDFPT. These demonstrations provide a critical milestone for the phase transitions of semiconducting polymers with conjugated side units.

\section{INTRODUCTION}

The excellent molecular designability of semiconducting polymers (SCPs) enables the fine tuning of optoelectronic properties $^{1}$ and equipment with specific functions, such as intrinsic stretchability, ${ }^{2}$ self-hearability, ${ }^{3,4}$ and biocompatibility. ${ }^{5,6}$ Owing to these unique advantages, SCPs have attracted attention as next-generation electronic materials. ${ }^{7,8}$ In terms of optimizing the optoelectronic properties of the SCPs, the introduction of conjugated side units, ${ }^{9-12}$ a fluorine atom, ${ }^{13-15}$ or both ${ }^{16-18}$ into the conjugated system has been used as an effective molecular design strategy. In addition, these bulky conjugated side units and the fluorine atom, which has the highest Pauling electronegativity, can induce alternation of the chain coplanarity and molecular interactions. In addition to the molecular design, the functional characteristics and mesoscopic scale morphology of the SCPs strongly correlate with their primary structures. ${ }^{19-26}$ Even if the chemical structures of polymers are completely the same, those characteristics can be changed dramatically. For instance, the backbone conformational changes lead to alteration in intermolecular packing and domain ordering. ${ }^{27}$ The differences in regioregularity ${ }^{28-30}$ and molecular weight ${ }^{31,32}$ influence their amorphousness and crystallographic orientation. Therefore, the elucidation of the relationships between the molecular design and morphological behaviors with well-defined SCPs is required for accessing novel conjugated building blocks and a deep understanding of their morphological characteristics.

Herein, we report the significant temperature-dependent morphological transitions of well-defined polythiophene derivatives with $m$-alkoxy-substituted fluoro-aryl side units. We demonstrate that the length of the alkyl chains on the fluoro-aryl side units is the key factor for determining the molecular conformation, ordering, and temperature-dependent transitions. Specifically, poly(3-(4-fluoro-3-(hexyloxy)phenyl)thiophene) (PHFPT) and poly(3-(4-fluoro-3-(dodecyloxy)phenyl)thiophene) (PDFPT) can be synthesized by a chaingrowth catalyst transfer polycondensation via the Kumada coupling reaction, ${ }^{33,34}$ generally called the Kumada catalyst transfer polycondensation (KCTP). The thiophene backbone is chosen as the main chain structure to obtain the applicability for controlled synthesis methods. In addition, we focused on the fluoro-aryl side unit for optimizing the optoelectronic properties for the above reasons. In terms of the $2 \mathrm{D}$-extended conjugation,

Received: November 11, 2020

Accepted: December 9, 2020

Published: December 17, 2020 
Scheme 1. General Synthetic Procedure of Monomer and Polymer Materials

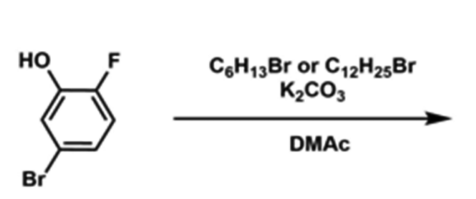

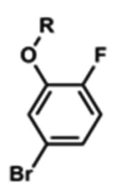

1: $\mathrm{R}=\mathrm{C}_{6} \mathrm{H}_{13}$

2: $\mathbf{R}=\mathrm{C}_{12} \mathrm{H}_{25}$

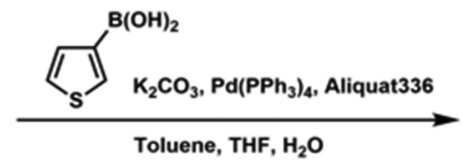

Toluene, THF, $\mathrm{H}_{2} \mathrm{O}$

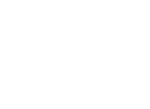

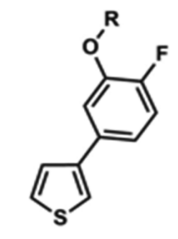

3: $\mathbf{R}=\mathrm{C}_{6} \mathrm{H}_{13}$ 4: $\mathrm{R}=\mathrm{C}_{12} \mathrm{H}_{25}$<smiles>[R]Oc1cc(-c2ccsc2)ccc1F</smiles>
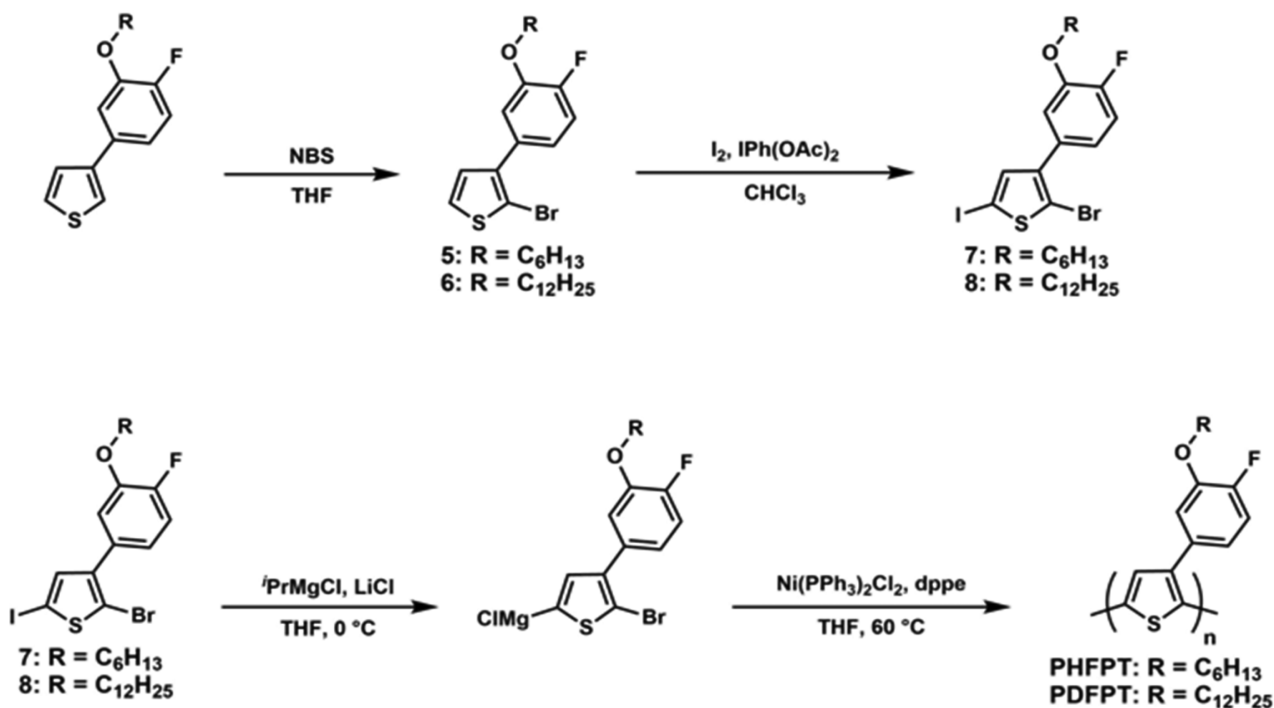

several polythiophene derivatives with conjugated side units have been reported. ${ }^{35-46}$ Additionally, poly(3-(4fluorophenyl)thiophene) (PFPT), which has a polythiophene backbone and fluoro-aryl side unit, has been reported for electrochemical capacitor applications. ${ }^{47-52}$ However, these PFPTs were synthesized by electrochemical polymerization and are insoluble in typically used organic solvents. Hence, we introduce the alkyl chains onto the fluoro-aryl unit for the designing of PHFPT and PDFPT, which enable them to be synthesized via solution reactions, affording good solution processability. The temperature-dependent behaviors of PHFPT and PDFPT shed light on the phase transitions of the SCPs with conjugated side chains.

\section{RESULTS AND DISCUSSION}

Synthesis of Polymers. In this study, we prepared welldefined fluoro-arylated polythiophene derivatives with $\mathrm{m}$ substituted alkoxy side chains of different lengths (Scheme 1 and Figure 1a). The detailed monomer and polymer synthesis protocols are available in the Supporting Information (Schemes S1 and S2 and Figures S1-S10). To achieve the controlled polymerization of the thiophene monomer with the electronwithdrawing fluoro-aryl unit, we first investigated the Grignard exchange reaction of 7 and 8 . The reaction of the monomers was carried out with an equivalent of ${ }^{i} \mathrm{PrMgCl}$ in the presence of $\mathrm{LiCl}$ dissolved in THF at $0^{\circ} \mathrm{C}$ for $40 \mathrm{~min}$ followed by quenching with $5 \mathrm{M} \mathrm{HCl}$ aq. The ${ }^{1} \mathrm{H}$ NMR spectra confirmed the quantitative $\mathrm{Mg}-\mathrm{I}$ exchange at the 5-position of the thiophene ring for the resulting products from 7 and 8 . Based on these results, the KCTP of 7 and 8 proceeded with $\mathrm{Ni}$ (dppe) $\mathrm{Cl}_{2}$ in THF at $60^{\circ} \mathrm{C}$ for $1 \mathrm{~h}$ to successfully obtain PHFPT and PDFPT with controlled number-average molecular weights $\left(M_{n} s\right)$, narrow molecular weight distributions $\left(M_{\mathrm{w}} / M_{\mathrm{n}} \mathrm{s}\right)$, and high regioregularity (r.r.) of 94 and 93\%, respectively (Table 1). These $M_{n}$ values could be controlled by changing the feed ratio of the monomer and Ni catalyst while maintaining low $M_{\mathrm{w}} / M_{\mathrm{n}}$ values (Figures S11 and S12 and Tables S1 and S2), and the samples shown in Table 1 were used in the latter section. For comparison, we also prepared a well-defined regioregular poly(3-hexylthiophene) (P3HT) $\left(M_{\mathrm{n}}=12,000, M_{\mathrm{w}} / M_{\mathrm{n}}=\right.$ 1.07 , and r.r. $=98 \%)$ by KCTP.

Energy Levels and Thermal Properties. The highest occupied molecular orbital (HOMO) energy levels for the obtained polymers were measured using a photoelectron spectrometer to investigate the effect of introducing electronwithdrawing fluoro-aryl units on the thiophene backbone. As predicted, both PHFPT and PDFPT showed deeper HOMO energy levels than P3HT $(-4.7 \mathrm{eV})$ due to their strong electronwithdrawing side units (Figure $1 \mathrm{~b}$ and Figure S13). In addition, we found that their backbone coplanarity and energy levels strongly correlate with the thermal annealing temperature and the length of the alkoxy substituents. The HOMO energy level of PDFPT, which has a long alkoxy chain, significantly shifts by thermal annealing. Its HOMO energy level rises to -5.21 from $-5.62 \mathrm{eV}$ (as-cast film) following annealing at $100{ }^{\circ} \mathrm{C}$. Furthermore, this increase in the HOMO energy level becomes deeper again after annealing at $150{ }^{\circ} \mathrm{C}$. These results indicate that the PDFPT backbone planarity and chain ordering significantly change with the thermal treatments. ${ }^{53}$ The morphological ordering of the PDFPT film increased at 100 ${ }^{\circ} \mathrm{C}$ compared to the as-cast film and then decreased again after annealing at $150{ }^{\circ} \mathrm{C}$. This temperature-dependent change in HOMO energy level is only observed in PDFPT. In PHFPT, which has a short alkoxy chain, it exhibited minor changes in the 
a

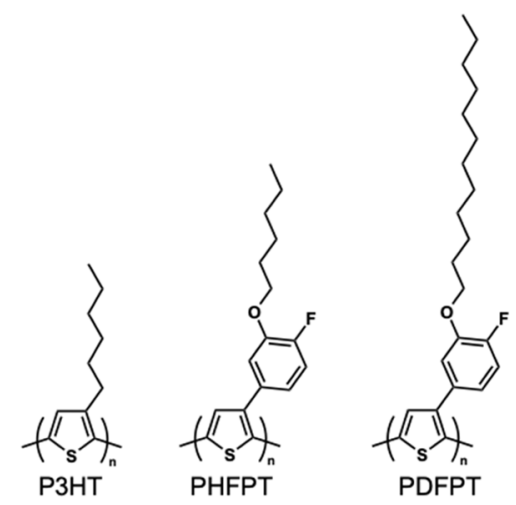

C

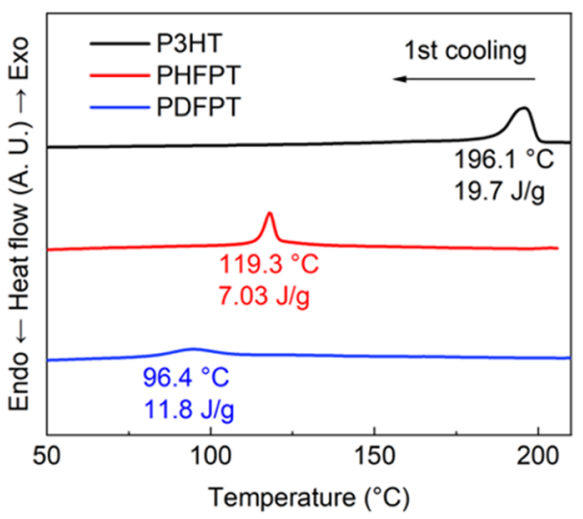

b
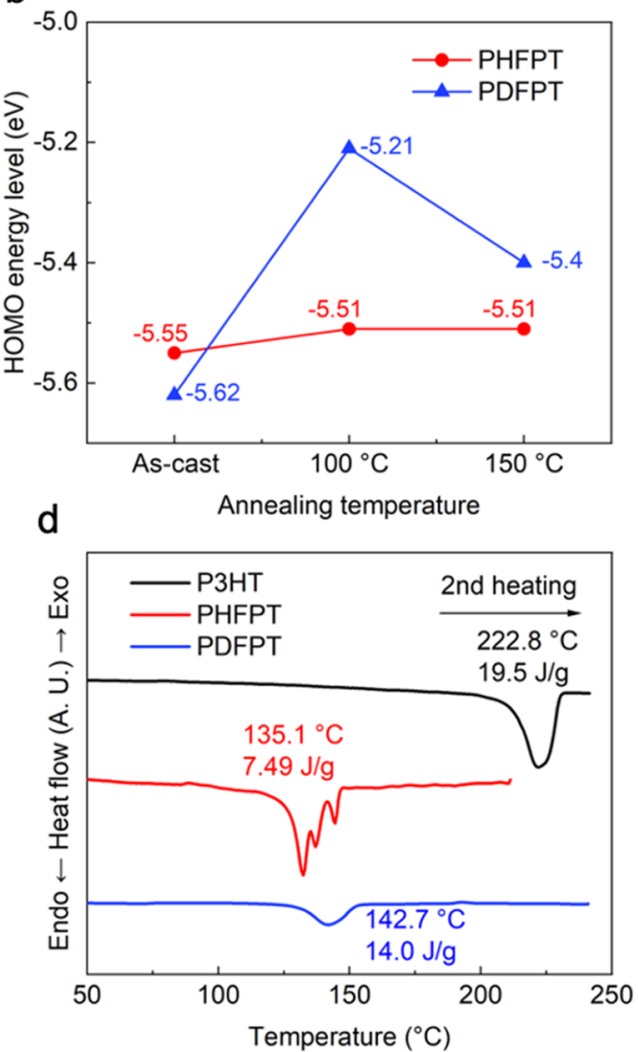

Figure 1. Energy levels and thermal characteristics of polymers. (a) Chemical structures of studied polymers. (b) Temperature-dependent HOMO energy levels of PHFPT and PDFPT. (c) First cooling cycle DSC thermograms of P3HT, PHFPT, and PDFPT. (d) Second heating cycle DSC thermograms of P3HT, PHFPT, and PDFPT.

Table 1. Synthesis of Fluoro-Arylated Polythiophenes

$\begin{array}{ccccc}\text { sample } & M_{\mathrm{n}}{ }^{a} & M_{\mathrm{w}} / M_{\mathrm{n}}{ }^{a} & \text { r.r. }(\%)^{b} & \text { yield (\%) } \\ \text { PHFPT } & 12,100 & 1.14 & 94 & 66 \\ \text { PDFPT } & 12,100 & 1.05 & 93 & 54\end{array}$

${ }^{a}$ Determined by SEC using a calibration with polystyrene standards in THF at $40{ }^{\circ} \mathrm{C} .{ }^{b}$ Head-to-tail regioregularity determined by ${ }^{1} \mathrm{H}$ NMR spectra, comparing the signal intensities of thiophene protons at 4position.

HOMO energy levels at the different annealing temperatures. These unchanged deep HOMO energy levels suggest that PHFPT has a twisted thiophene backbone, which is possibly due to the bulky side units, and this chain conformation is not altered by the thermal treatments.

To understand the correlation between the thermal transition behavior and chemical structures of the studied polymers, the differential scanning calorimetry (DSC) measurement was performed. The melting and crystalline temperatures of the fluoro-arylated polymers largely decreased compared to P3HT (Figure 1c,d). Note that the melting temperatures $\left(T_{\mathrm{m}}\right)$ of PHFPT and PDFPT are observed to be below $150{ }^{\circ} \mathrm{C}$. The temperature-dependent energy level changes of PDFPT can be explained based on this result. The thermal treatment over the $T_{\mathrm{m}}$ destroys the planarized backbone conformation and ordered morphology, which was formed by annealing at $100{ }^{\circ} \mathrm{C}$. The relative crystalline information can be extracted from the heat of fusion of each polymer. The heat of fusion of PHFPT clearly shows a lower value than those of PDFPT and P3HT. This result also supports the twisted backbone conformation of PHFPT, disturbing the well-ordered morphology.

Optical Properties. Indeed, we observed that the backbone planarity of the fluoro-arylated polymers can be readily alternated by thermal treatment, even in the film state based on investigation of the optical properties. These temperaturedependent conformational changes strongly correlate with the length of the alkoxy substituents. To understand their intra- and interpolymer chain conformations, ultraviolet-visible (UVvis) spectroscopy was performed. All the polymers were well dissolved in chloroform, and their solution state spectra showed similar monomodal absorbance peaks associated with the coillike chain conformation (Figure 2a). The peaks for both fluoroarylated polymers clearly redshifted compared with those for $\mathrm{P} 3 \mathrm{HT}$, indicating the extended conjugation of the isolated polymer chains. On the other hand, the spin-coated films of the fluoro-arylated polymers exhibit almost the same absorbance spectra as their solution state (Figure 2c,d). These results indicate that the twisted coil-like backbone conformation is maintained in the film state. This is similar to the chain conformation in solution and solid state of the regio-irregular P3HTs, which have twisted backbones due to the large steric hindrance of each alkyl side chain. ${ }^{54}$ In general, the film spectra for the regioregular P3HT deposited from good solvents show a significant redshift and defined vibronic peaks due to the backbone planarization with an extended conjugation system and well-ordered intermolecular $\pi$-stacked aggregate formation (Figure $2 \mathrm{~b}$ ). Thus, the bulky $m$-alkoxy-substituted fluoro-aryl units may disturb the backbone coplanarity and intermolecular aggregations. From the spectra of PHFPT films, negligible 
a

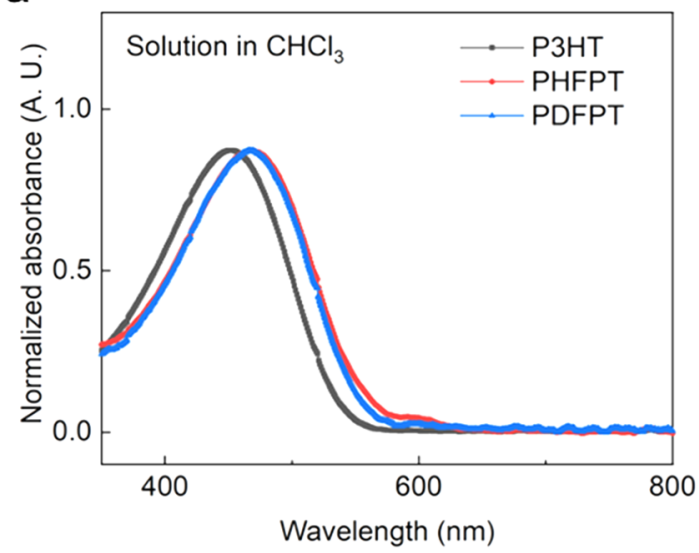

C

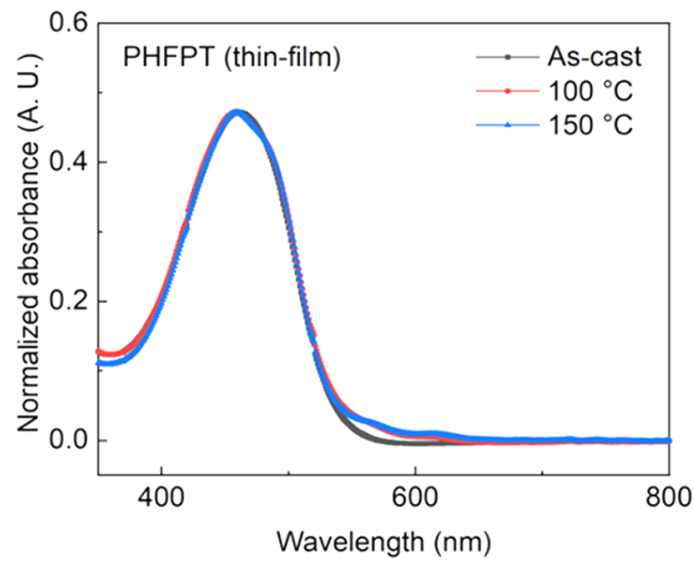

e

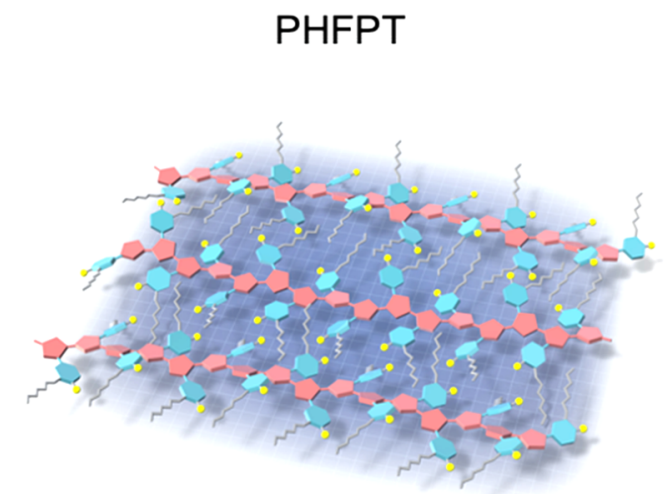

twisted thiophene backbone b

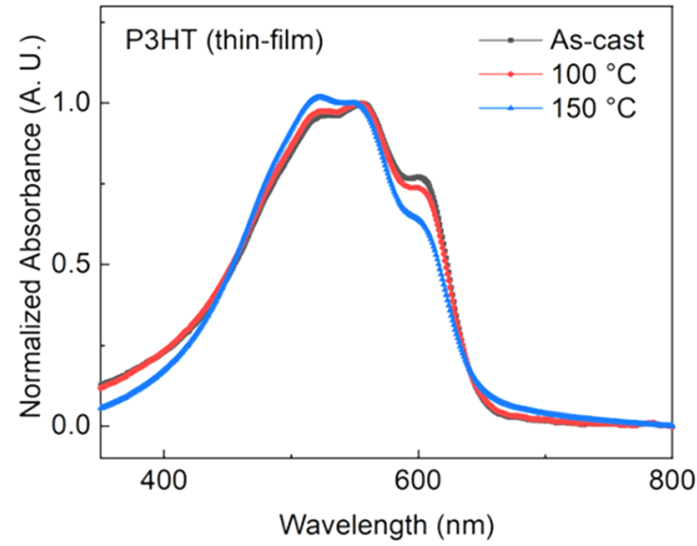

d

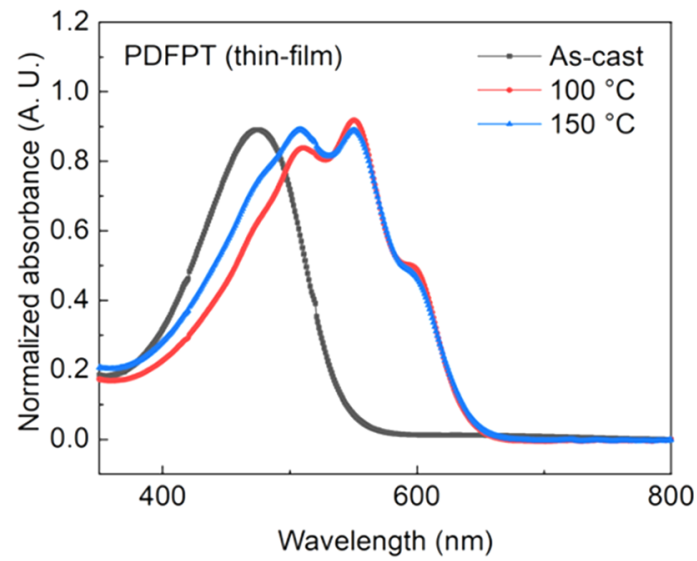

f

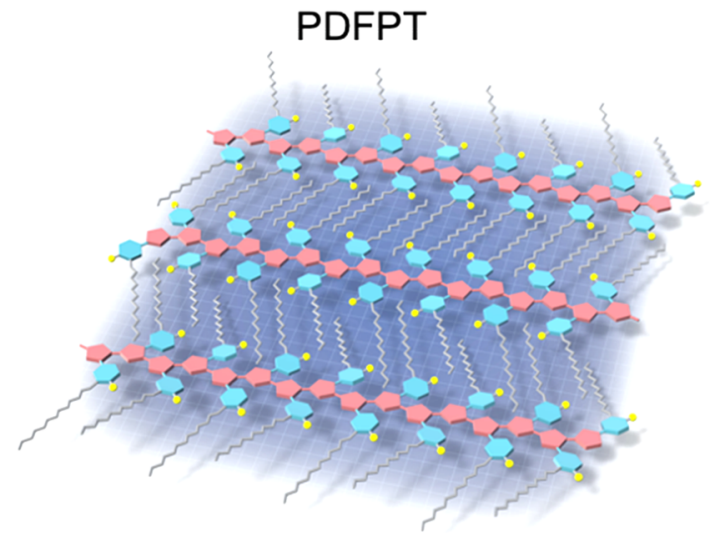

Planar thiophene backbone

Figure 2. Optical properties of polymers. (a) Normalized absorption spectra of P3HT, PHFPT, and PDFPT solutions in $\mathrm{CHCl}_{3}$. (b-d) Normalized absorption spectra of P3HT, PHFPT, and PDFPT thin films annealed at various temperatures. (e) Schematic illustration of the twisted backbone of PHFPT. (f) Schematic illustration of the planarized backbone of PDFPT.

changes were observed at both thermal annealing temperatures of 100 and $150{ }^{\circ} \mathrm{C}$. In contrast, the spectra for PDFPT films show drastic improvements in the backbone planarity and interchain aggregation via thermal annealing even in the spincoated films (Figure $2 \mathrm{~d}$ and Table 2). Surprisingly, by measuring the film spectra of PDFPT in the range of room temperature to $115{ }^{\circ} \mathrm{C}$, we observed that this coil-to-rod conformational transformation starts at a low temperature of approximately 60 ${ }^{\circ} \mathrm{C}$ (Figure S15).

Hence, we hypothesize that the applied thermal energy may be consumed for the entanglement and interdigitation of the side chains in PHFPT due to the bulky side units and twisted backbone (Figure 2e). In addition, the long alkyl chain of PDFPT acts as a physical spacer and disturbs the crowded interdigitation of the side chain. Instead, the applied thermal 
Table 2. Absorbance Characteristics of Polymers

\begin{tabular}{clccc} 
sample & \multicolumn{1}{c}{ condition } & $\lambda_{\text {max }}(\mathrm{nm})$ & $\lambda_{\text {onset }}(\mathrm{nm})$ & $E_{\mathrm{g}}(\mathrm{eV})^{a}$ \\
P3HT & solution & 452 & 539 & 2.30 \\
& as-cast film & 555 & 645 & 1.92 \\
& $10{ }^{\circ} \mathrm{C}$ annealed film & 555 & 645 & 1.92 \\
PHFPT & solution & 468 & 557 & 2.23 \\
& as-cast film & 461 & 534 & 2.32 \\
& $100{ }^{\circ} \mathrm{C}$ annealed film & 458 & 533 & 2.33 \\
PDFPT & solution & 467 & 555 & 2.23 \\
& as-cast film & 475 & 540 & 2.30 \\
& $100{ }^{\circ} \mathrm{C}$ annealed film & 544 & 638 & 1.93
\end{tabular}

${ }^{a}$ Calculated from onset wavelengths in UV-vis spectra, where $E_{\mathrm{g}}=$ $1240 / \lambda_{\text {onset }}$.

energy is consumed for the thiophene backbone planarization in PDFPT (Figure 2f). Similar temperature-dependent morphological changes have been observed in a few previous reports focusing on the poly[3-(4-alkylphenyl)thiophene]s. ${ }^{55-57}$ However, the detailed mechanism for the conformational transformation and the molecular structural effects remains unexplained. Therefore, we scrutinized the nanolevel molecular ordering and packing structures, as discussed in a later section.

Temperature-Dependent Morphological Characteristics. Grazing incidence X-ray diffraction (GIXD) measurements were carried out to confirm our hypothesis and provide insights into the contrasting morphological behaviors between the PFHPT and PDFPT thin films. All the calculated crystallographic parameters are summarized in Table 3.

Table 3. GIXD Profiles of Polymers

$\begin{array}{clcc}\text { sample } & \text { film condition } & \text { lamellar spacing }(\mathrm{nm}) & \pi-\pi \text { stacking }(\mathrm{nm}) \\ \text { PHFPT } & \text { as-cast } & 1.62 & \text { NA } \\ & 100{ }^{\circ} \mathrm{C} \text { annealed } & 2.16,1.61,1.27 & 0.42 \\ & 150{ }^{\circ} \mathrm{C} \text { annealed } & 1.61,1.34 & 0.38 \\ \text { PDFPT } & \text { as-cast } & 2.23 & \text { NA } \\ & 100{ }^{\circ} \mathrm{C} \text { annealed } & 2.95 & 0.42 \\ & 150{ }^{\circ} \mathrm{C} \text { annealed } & 2.87 & \text { NA }\end{array}$

In the case of PHFPT, the as-cast film shows an isotropic diffraction, and it is difficult to find a (010) diffraction peak due to the $\pi-\pi$ stacking (Figure 3a). A lamellar distance of $1.62 \mathrm{~nm}$ was calculated from the (100) diffraction peak in the out-ofplane $\left(q_{z}\right)$ direction. This value is smaller than the lamellar distance of P3HT (1.65 nm) (Figure S15 and Table S3); even PHFPT has bulky side units. These results indicated that a less ordered packing structure is due to their twisted backbone and interdigitation of the side chains. Additionally, the $m$-substituted alkyl chain might be twisted away from the backbone to pack between the lamellar distances along with the neighboring thiophene main chains. ${ }^{40}$ This behavior is consistent with a previous report for the head-to-head, tail-to-tail regiostructurebased P3HT, which has a twisted backbone and shows a narrow lamellar distance of $1.25 \mathrm{~nm}$ due to its side-chain interdigitation. ${ }^{54}$ Interestingly, the $100{ }^{\circ} \mathrm{C}$-annealed PHFPT film shows small additional (100) peaks on either side of the main peak in the $q_{z}$ direction (Figure 3b,d). Additionally, a (010) diffraction peak can be observed in the in-plane $\left(q_{x y}\right)$ direction, giving a $\pi-\pi$ stacking distance of $0.42 \mathrm{~nm}$ (Figure $3 \mathrm{e}$ ). This suggests that the PHFPT chains are packed in an edge-on orientation, and their ordered structure is improved by the thermal treatment. The lamellar distance is calculated to be $1.61 \mathrm{~nm}$ from the main
(100) peak, which is almost the same as that for the as-cast film. The other additional peaks give the lamellar distances of 2.16 and $1.27 \mathrm{~nm}$. This result demonstrates that several phase transitions compete between avoiding and accelerating the crowded interdigitation for annealing at $100{ }^{\circ} \mathrm{C}$. Notably, the newly presented wider lamellar distance disappeared in the 150 ${ }^{\circ} \mathrm{C}$-annealed PHFPT film, where the thermal treatment temperature is over its $T_{\mathrm{m}}$ (Figure $3 \mathrm{c}$ ). The lamellar distances were determined to be 1.61 and $1.34 \mathrm{~nm}$ from the main (100) peak and the side peak at the higher $q_{z}$, respectively. Accordingly, the interdigitation of the side chains was accelerated by the thermal treatments in the PHFPT films, as we hypothesized. In terms of PDFPT, the as-cast film also shows an isotropic diffraction, and it is difficult to find the (010) diffraction peak due to $\pi-\pi$ stacking similar to that of PHFPT. On the other hand, the calculated lamellar distance is $2.23 \mathrm{~nm}$, which corresponds to a wider lamellar distance than P3HT and PHFPT (Figure 3f). Note that the lamellar distance in the PDFPT film annealed at $100{ }^{\circ} \mathrm{C}$ was determined to be $2.95 \mathrm{~nm}$ without any side peaks, which is wider than that in the as-cast film (Figure 3g,i). Furthermore, the edge-on orientation of the PDFPT chains and increasing ordered packing structures are confirmed due to the observation of the highly ordered diffraction peaks in the $q_{z}$ direction and the (010) diffraction peak in the $q_{x y}$ direction (Figure $3 \mathrm{j}$ ). In the annealed film at 150 ${ }^{\circ} \mathrm{C}$, a relatively wide lamellar distance is maintained, but the highly ordered structures disappear (Figure $3 \mathrm{~h}$ ). This is probably because of the melting impact of the PDFPT crystalline domains as the $T_{\mathrm{m}}$ value of PDFPT is found below $150{ }^{\circ} \mathrm{C}$ from the DSC measurement (Figure 1d). The long alkyl chain on PDFPT physically disturbs the crowded interdigitation of each side chain, forming a wide lamellar distance. Simultaneously, these physical spacers at the lamellar spacing enable enhancement of the backbone planarity and ordered polymer chain aggregations. This morphological behavior is in agreement with the optoelectrical and thermal properties, as already discussed above.

\section{CONCLUSIONS}

In summary, we have successfully developed conjugated building blocks, which can be synthesized by a controlled polymerization, with tunable optoelectrical characteristics by introducing the $m$-alkoxy-substituted fluoro-aryl moieties onto a polythiophene backbone. Our designed polymers show deeplying HOMO energy levels $(-5.62$ to $-5.21 \mathrm{eV})$ owing to the presence of electron-withdrawing side units and a twisted backbone conformation. Furthermore, we find that the twisted backbones are readily planarized by a thermal treatment even in the film state. These temperature-dependent conformational transitions strongly correlate with the length of the alkyl substituents on the fluoro-aryl side units. The intermolecular interdigitation and narrow lamellar spacing are promoted by thermal annealing due to their twisted backbone in the PHFPT film, which has a short alkyl chain. On the other hand, the long alkyl chains in PDFPT behave as physical spacers and disturb the crowded interdigitation. Consequently, the applied thermal energy is consumed for the thiophene backbone planarization in PDFPT. Hence, our demonstrated insights into the phasetransition behaviors present a significant milestone in the design of semiconducting polymers with conjugated side-chain units. 
a

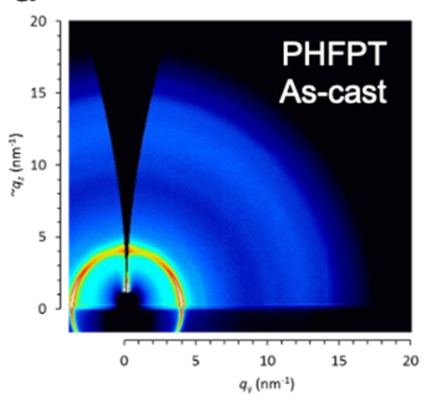

d

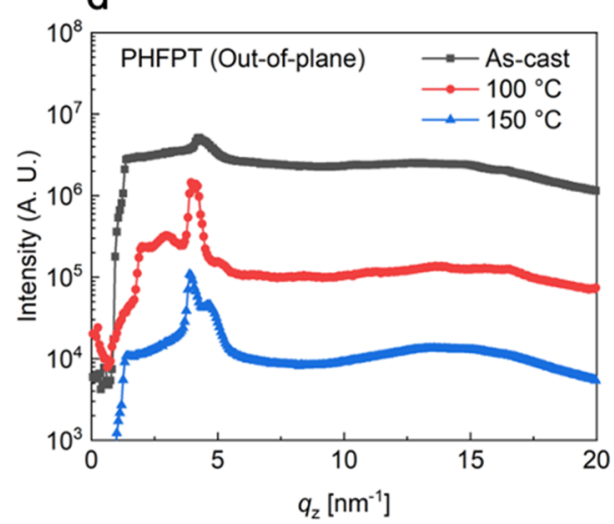

f

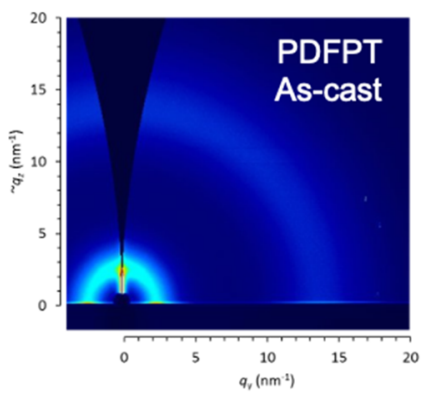

i

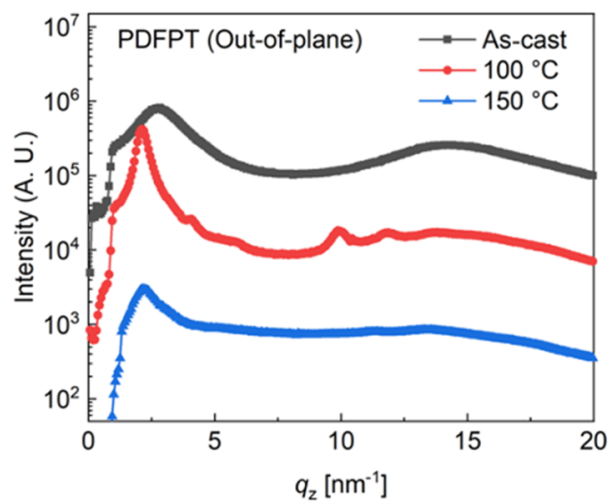

b

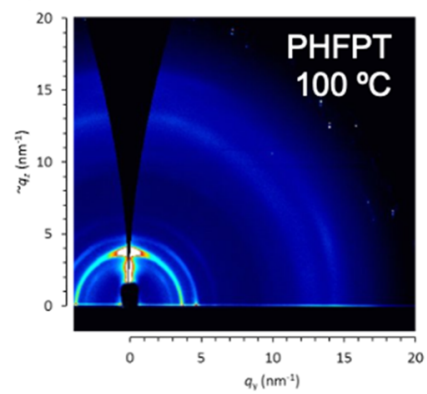

C

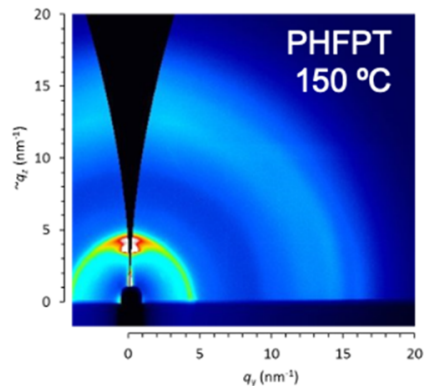

e

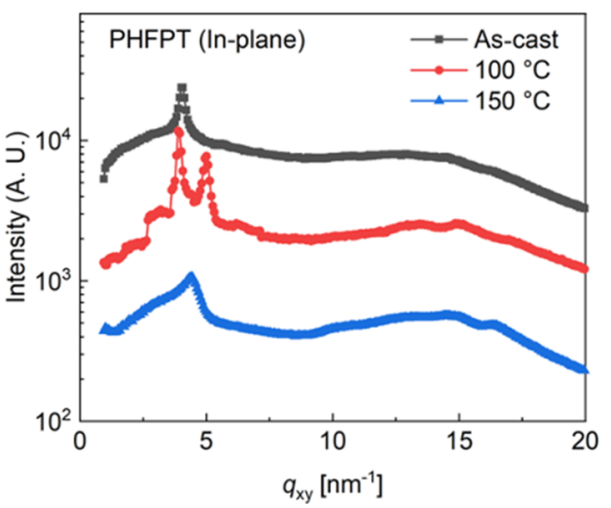

h
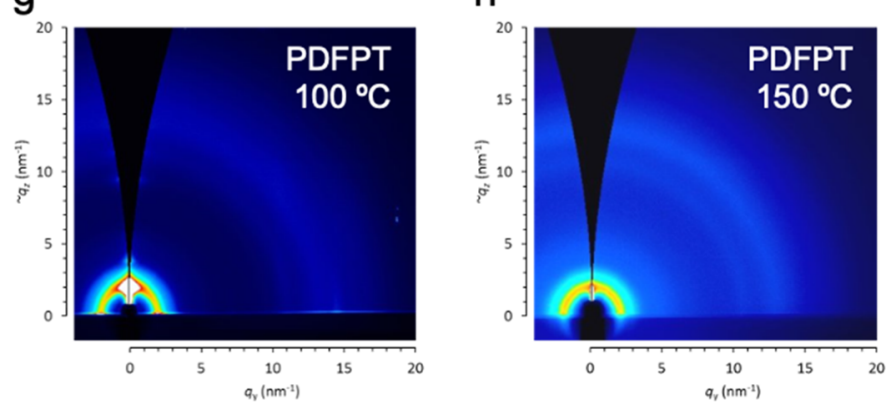

j

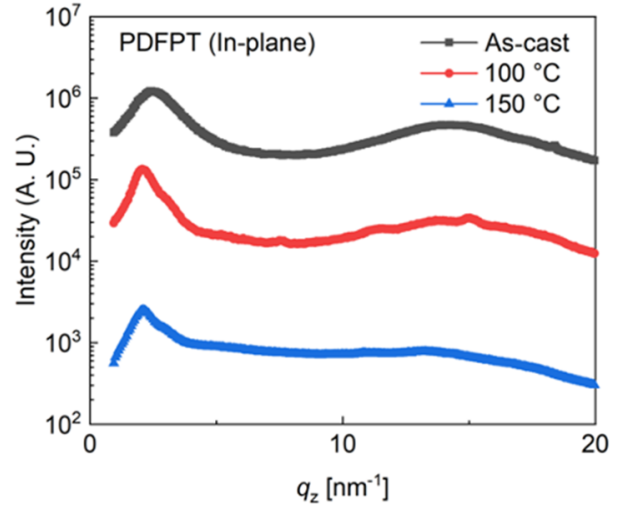

Figure 3. GIXD profiles of polymers. $(a-c) 2 D$ GIXD images of PHFPT thin films annealed at various temperatures. (d, e) 1D GIXD profiles of PHFPT along with the out-of-plane direction $(\mathrm{d})$ and in-plane direction $(\mathrm{e})$. $(\mathrm{f}-\mathrm{h})$ 2D GIXD images of PDFPT thin films annealed at various temperatures. ( $i, j)$ 1D GIXD profiles of PDFPT along with the out-of-plane direction (i) and in-plane direction (j).

\section{EXPERIMENTAL SECTION}

Materials. All reagents were purchased from Tokyo Chemical Industry Co., Ltd., Wako Chemicals Co., Ltd., and Sigma-Aldrich. THF (99.5\%, stabilizer-free, Wako Chemicals Co., Ltd.) was refluxed over sodium benzophenone under nitrogen for $2 \mathrm{~h}$ and then distilled just before use. Other commercial reactants were used without further purification.

General Procedure for the Synthesis of Polymers. A 30 $\mathrm{mL}$ two-neck flask with lithium chloride (5 equiv) was heated using a heat gun under reduced pressure. After the flask was 
cooled down to room temperature under a $\mathrm{N}_{2}$ gas atmosphere, 3-(3-alkoxy-4-fluorophenyl)-2-bromo-5-iodothiophene (7 or 8) $\left(0.2 \mathrm{~g}, 1\right.$ equiv) was added. After purging with $\mathrm{N}_{2}$ gas, anhydrous THF ( $15 \mathrm{~mL}$ ) was added, and the solution was cooled down to 0 ${ }^{\circ} \mathrm{C}$. The ${ }^{i} \mathrm{PrMgCl}$ solution (1.3 M in THF, 1.05 equiv) was then slowly added dropwise via a syringe. After complete addition, the reaction was stirred for $30 \mathrm{~min}$ at room temperature. To another $10 \mathrm{~mL}$ two-neck flask, bis(triphenylphosphino) $\mathrm{Ni}(\mathrm{II})$ dichloride and 1,2-bis(diphenylphosphino)ethane were added. After purging with $\mathrm{N}_{2}$ gas, the mixture was dissolved in anhydrous THF ( $5 \mathrm{~mL}$ ). Afterward, the prepared $\mathrm{Ni}$ (dppe) $\mathrm{Cl}_{2}$ solution was quickly injected into the prepared Grignard thiophene monomer precursor solution via a syringe to start the Kumada catalyst transfer polycondensation. Polymerization was carried out for $1 \mathrm{~h}$ at $60^{\circ} \mathrm{C}$ followed by quenching with a 5 $\mathrm{M} \mathrm{HCl}$ solution. The crude solution was poured into a mixture solution of methanol $(200 \mathrm{~mL})$ and water $(100 \mathrm{~mL})$, and the precipitate was filtered and loaded to an extraction thimble and left in a Soxhlet extractor. The crude polymer was successively extracted with methanol and acetone, and then the objected polymer was collected by chloroform. The obtained chloroform solution was concentrated and dried under high vacuum overnight to give poly(3-(4-fluoro-3-(hexyloxy)phenyl)thiophene) (PHFPT) and poly(3-(4-fluoro-3-(dodecyloxy)phenyl)thiophene) (PDFPT).

General Measurements and Characterizations. ${ }^{1} \mathrm{H}$ NMR spectra were recorded with a JOEL JNM-ECX400 spectrometer at $25{ }^{\circ} \mathrm{C}$. Deuterated chloroform was used as a solvent with trimethylsilane as a standard. Number- and weightaverage molecular weights $\left(M_{\mathrm{n}}\right.$ and $\left.M_{\mathrm{w}}\right)$ were measured by SEC on a JASCO GULLIVER 1500 equipped with a pump, an absorbance detector ( $\mathrm{UV}, \lambda=254 \mathrm{~nm}$ ), and two polystyrene gel columns, based on a conventional calibration curve using polystyrene standards. THF $\left(40{ }^{\circ} \mathrm{C}\right)$ was used as a carrier solvent at a flow rate of $1.0 \mathrm{~mL} / \mathrm{min}$. The highest occupied molecular orbital (HOMO) energy level was determined with a PESA: Riken AC-2 photoelectron spectrometer. Thermal analysis was performed on a Seiko EXSTAR 6000 TG/DTA 6300 thermal analyzer at a heating rate of $10{ }^{\circ} \mathrm{C} / \mathrm{min}$ for thermogravimetry (TG) and a TA Instruments Q-100 connected to a cooling system at a heating rate of $10{ }^{\circ} \mathrm{C} / \mathrm{min}$ for differential scanning calorimetry (DSC). UV-vis absorption spectra of the polymer solution and thin films were recorded using a Hitachi U-4100 spectrophotometer. The polymer thin film samples for UV-vis measurements were spin-coated at $1000 \mathrm{rpm}$ for $60 \mathrm{~s}$ onto glass substrates from chloroform solutions $\left(20 \mathrm{mg} \mathrm{mL}^{-1}\right)$. Tapping mode AFM observation was performed with an Agilent AFM 5500 using microfabricated cantilevers with a force constant of $34 \mathrm{~N} / \mathrm{m}$. The grazing incidence X-ray diffraction (GIXD) measurements were conducted at the beamline BL46XU of SPring-8, Japan. The polymer thin film samples for GIXD measurements were spincoated at $1000 \mathrm{rpm}$ for $60 \mathrm{~s}$ onto Si wafers from chloroform solutions $\left(20 \mathrm{mg} \mathrm{mL}^{-1}\right)$. The sample was irradiated at a fixed incident angle $\alpha_{i}$ on the order of $0.12^{\circ}$ through a Huber diffractometer with an X-ray energy of $12.398 \mathrm{keV}(\lambda=0.10002$ $\mathrm{nm}$ ), and the GIXD patterns were recorded with a $2 \mathrm{D}$ image detector (Pilatus $300 \mathrm{~K}$ ) with the sample-to-detector distances of $174.1 \mathrm{~mm}$.

\section{ASSOCIATED CONTENT}

\section{Supporting Information}

The Supporting Information is available free of charge at https://pubs.acs.org/doi/10.1021/acsomega.0c05514.

Experimental details of monomer and polymer syntheses, ${ }^{1} \mathrm{H}$ and ${ }^{13} \mathrm{C}$ NMR spectra of monomer compounds, ${ }^{1} \mathrm{H}$ NMR spectra of polymers, controlled polymerization results, photoelectron spectra, TGA thermograms, UVvis absorption spectra, 2D GIWAXS profiles, and AFM images (PDF)

\section{AUTHOR INFORMATION}

\section{Corresponding Author}

Tomoya Higashihara - Department of Organic Materials Science, Yamagata University, Yonezawa, Yamagata 992 8510, Japan; 이이.org/0000-0003-2115-1281;

Email: thigashihara@yz.yamagata-u.ac.jp

\section{Author}

Yuto Ochiai - Department of Organic Materials Science, Yamagata University, Yonezawa, Yamagata 992-8510, Japan

Complete contact information is available at:

https://pubs.acs.org/10.1021/acsomega.0c05514

\section{Author Contributions}

Y.O. and T.H. designed the project and experiments. Y.O. synthesized and characterized all of the monomer compounds and semiconducting polymers. Y.O. organized the data and wrote the manuscript. All authors reviewed and commented on the manuscript. T.H. directed the project.

\section{Notes}

The authors declare no competing financial interest.

\section{ACKNOWLEDGMENTS}

Y.O. was supported by Japan Society for the Promotion of Science (JSPS) Research Fellowship for Young Scientists (proposal no. 18J21080) and Innovative Flex Course for Frontier Organic Material Systems (iFront) at Yamagata University. GIXD measurement was carried out at the BL46XU of SPring-8 with the approval of the Japan Synchrotron Radiation Research Institute (JASRI) (proposal no. 2018A1794). We thank Dr. Keisuke Tajima (RIKEN, Japan) for the kind assistance in measuring PESA AC-2 and for productive discussions. We thank Dr. Tomoyuki Koganezawa (JASRI, Japan) for the kind assistance in measuring GIXD.

\section{REFERENCES}

(1) Bronstein, H.; Nielsen, C. B.; Schroeder, B. C.; McCulloch, I. The Role of Chemical Design in the Performance of Organic Semiconductors. Nat. Rev. Chem. 2020, 4, 66-77.

(2) Wang, G. J. N.; Gasperini, A.; Bao, Z. Stretchable Polymer Semiconductors for Plastic Electronics. Adv. Electron. Mater. 2018, 4, 1700429.

(3) Oh, J. Y.; Rondeau-Gagné, S.; Chiu, Y. C.; Chortos, A.; Lissel, F.; Wang, G. J. N.; Schroeder, B. C.; Kurosawa, T.; Lopez, J.; Katsumata, T.; Xu, J.; Zhu, C.; Gu, X.; Bae, W. G.; Kim, Y.; Jin, L.; Chung, J. W.; Tok, J. B. H.; Bao, Z. Intrinsically Stretchable and Healable Semiconducting Polymer for Organic Transistors. Nature 2016, 539, $411-415$.

(4) Oh, J. Y.; Son, D.; Katsumata, T.; Lee, Y.; Kim, Y.; Lopez, J.; Wu, H. C.; Kang, J.; Park, J.; Gu, X.; Mun, J.; Wang, N. G. J.; Yin, Y.; Cai, W.; Yun, Y.; Tok, J. B. H.; Bao, Z. Stretchable Self-Healable Semi- 
conducting Polymer Film for Active-Matrix Strain-Sensing Array. Sci. Adv. 2019, 5, eaav3097.

(5) Lei, T.; Guan, M.; Liu, J.; Lin, H. C.; Pfattner, R.; Shaw, L.; McGuire, A. F.; Huang, T. C.; Shao, L.; Cheng, K. T.; Tok, J. B. H.; Bao, Z. Biocompatible and Totally Disintegrable Semiconducting Polymer for Ultrathin and Ultralightweight Transient Electronics. Proc. Natl. Acad. Sci. U. S. A. 2017, 114, 5107-5112.

(6) Jiang, Y.; Upputuri, P. K.; Xie, C.; Zeng, Z.; Sharma, A.; Zhen, X.; Li, J.; Huang, J.; Pramanik, M.; Pu, K. Metabolizable Semiconducting Polymer Nanoparticles for Second Near-Infrared Photoacoustic Imaging. Adv. Mater. 2019, 31, 1808166.

(7) Someya, T.; Amagai, M. Toward a New Generation of Smart Skins. Nat. Biotechnol. 2019, 37, 382-388.

(8) Yang, J. C.; Mun, J.; Kwon, S. Y.; Park, S.; Bao, Z.; Park, S. Electronic Skin: Recent Progress and Future Prospects for SkinAttachable Devices for Health Monitoring, Robotics, and Prosthetics. Adv. Mater. 2019, 31, 1904765.

(9) Shin, J.; Kim, M.; Lee, J.; Sin, D.; Kim, H. G.; Hwang, H.; Cho, K. Effects of Conformational Symmetry in Conjugated Side Chains on Intermolecular Packing of Conjugated Polymers and Photovoltaic Properties. RSC Adv. 2015, 5, 106044-106052.

(10) Xu, X.; Li, Z.; Bäcke, O.; Bini, K.; James, D. I.; Olsson, E.; Andersson, M. R.; Wang, E. Effects of Side Chain Isomerism on the Physical and Photovoltaic Properties of Indacenodithieno[3,2-b]Thiophene-Quinoxaline Copolymers: Toward a Side Chain Design for Enhanced Photovoltaic Performance. J. Mater. Chem. A 2014, 2, 18988-18997.

(11) Li, X.; Huang, G.; Chen, W.; Jiang, H.; Qiao, S.; Yang, R. Size Effect of Two-Dimensional Conjugated Space in Photovoltaic Polymers' Side Chain: Balancing Phase Separation and Charge Transport. ACS Appl. Mater. Interfaces 2020, 12, 16670-16678.

(12) Huang, Y.-W.; Lin, Y.-C.; Wu, Y.-S.; Wong, Y.-T.; Kuo, M.-Y.; Chen, W.-C.; Chueh, C.-C. Structure-Mobility Relationship of Benzodithiophene-Based Conjugated Polymers with Varied Biaxially Extended Conjugated Side Chains. Ind. Eng. Chem. Res. 2020, 59, 9105-9115.

(13) Babudri, F.; Farinola, G. M.; Naso, F.; Ragni, R. Fluorinated Organic Materials for Electronic and Optoelectronic Applications: The Role of the Fluorine Atom. Chem. Commun. 2007, 1003-1022.

(14) Tang, M. L.; Bao, Z. Halogenated Materials as Organic Semiconductors. Chem. Mater. 2011, 23, 446-455.

(15) Chen, H. Y.; Hou, J.; Zhang, S.; Liang, Y.; Yang, G.; Yang, Y.; Yu, L.; Wu, Y.; Li, G. Polymer Solar Cells with Enhanced Open-Circuit Voltage and Efficiency. Nat. Photonics 2009, 3, 649-653.

(16) Oh, J.; Kranthiraja, K.; Lee, C.; Gunasekar, K.; Kim, S.; Ma, B.; Kim, B. J.; Jin, S. H. Side-Chain Fluorination: An Effective Approach to Achieving High-Performance All-Polymer Solar Cells with Efficiency Exceeding 7\%. Adv. Mater. 2016, 28, 10016-10023.

(17) Shin, J.; Kim, M.; Kang, B.; Lee, J.; Kim, H. G.; Cho, K. Impact of Side-Chain Fluorination on Photovoltaic Properties: Fine Tuning of the Microstructure and Energy Levels of 2D-Conjugated Copolymers. J. Mater. Chem. A 2017, 5, 16702-16711.

(18) Shin, J.; Kim, M.; Lee, J.; Kim, H. G.; Hwang, H.; Cho, K. Positional Effects of Fluorination in Conjugated Side Chains on Photovoltaic Properties of Donor-Acceptor Copolymers. Chem. Commun. 2017, 53, 1176-1179.

(19) Noriega, R.; Rivnay, J.; Vandewal, K.; Koch, F. P. V.; Stingelin, N.; Smith, P.; Toney, M. F.; Salleo, A. A General Relationship between Disorder, Aggregation and Charge Transport in Conjugated Polymers. Nat. Mater. 2013, 12, 1038-1044.

(20) Szarko, J. M.; Guo, J.; Liang, Y.; Lee, B.; Rolczynski, B. S.; Strzalka, J.; Xu, T.; Loser, S.; Marks, T. J.; Yu, L.; Chen, L. X. When Function Follows Form: Effects of Donor Copolymer Side Chains on Film Morphology and BHJ Solar Cell Performance. Adv. Mater. 2010, $22,5468-5472$.

(21) Rieger, R.; Beckmann, D.; Mavrinskiy, A.; Kastler, M.; Müllen, K. Backbone Curvature in Polythiophenes. Chem. Mater. 2010, 22, 53145318.
(22) Osaka, I.; Abe, T.; Shinamura, S.; Takimiya, K. Impact of Isomeric Structures on Transistor Performances in Naphthodithiophene Semiconducting Polymers. J. Am. Chem. Soc. 2011, 133, 68526860.

(23) Ko, S.; Hoke, E. T.; Pandey, L.; Hong, S.; Mondal, R.; Risko, C.; Yi, Y.; Noriega, R.; McGehee, M. D.; Brédas, J. L.; Salleo, A.; Bao, Z. Controlled Conjugated Backbone Twisting for an Increased OpenCircuit Voltage While Having a High Short-Circuit Current in Poly(Hexylthiophene) Derivatives. J. Am. Chem. Soc. 2012, 134, 5222-5232.

(24) Chen, M. S.; Niskala, J. R.; Unruh, D. A.; Chu, C. K.; Lee, O. P.; Fréchet, J. M. J. Control of Polymer-Packing Orientation in Thin Films through Synthetic Tailoring of Backbone Coplanarity. Chem. Mater. 2013, 25, 4088-4096.

(25) Osaka, I.; Saito, M.; Koganezawa, T.; Takimiya, K. ThiopheneThiazolothiazole Copolymers: Significant Impact of Side Chain Composition on Backbone Orientation and Solar Cell Performances. Adv. Mater. 2014, 26, 331-338.

(26) Liu, X.; He, B.; Garzón-Ruiz, A.; Navarro, A.; Chen, T. L.; Kolaczkowski, M. A.; Feng, S.; Zhang, L.; Anderson, C. A.; Chen, J.; Liu, Y. Unraveling the Main Chain and Side Chain Effects on Thin Film Morphology and Charge Transport in Quinoidal Conjugated Polymers. Adv. Funct. Mater. 2018, 28, 1801874.

(27) Park, K. S.; Kwok, J. J.; Dilmurat, R.; Qu, G.; Kafle, P.; Luo, X.; Jung, S. H.; Olivier, Y.; Lee, J. K.; Mei, J.; Beljonne, D.; Diao, Y. Tuning Conformation, Assembly, and Charge Transport Properties of Conjugated Polymers by Printing Flow. Sci. Adv. 2019, 5, eaaw7757.

(28) Perez, L. A.; Zalar, P.; Ying, L.; Schmidt, K.; Toney, M. F.; Nguyen, T. Q.; Bazan, G. C.; Kramer, E. J. Effect of Backbone Regioregularity on the Structure and Orientation of a Donor-Acceptor Semiconducting Copolymer. Macromolecules 2014, 47, 1403-1410.

(29) Li, X.; Wolanin, P. J.; MacFarlane, L. R.; Harniman, R. L.; Qian, J.; Gould, O. E. C.; Dane, T. G.; Rudin, J.; Cryan, M. J.; Schmaltz, T.; Frauenrath, H.; Winnik, M. A.; Faul, C. F. J.; Manners, I. Uniform Electroactive Fibre-like Micelle Nanowires for Organic Electronics. Nat. Commun. 2017, 8, 15909.

(30) Park, H.; Ma, B. S.; Kim, J. S.; Kim, Y.; Kim, H. J.; Kim, D.; Yun, H.; Han, J.; Kim, F. S.; Kim, T. S.; Kim, B. J. Regioregular- BlockRegiorandom Poly(3-Hexylthiophene) Copolymers for Mechanically Robust and High-Performance Thin-Film Transistors. Macromolecules 2019, 52, 7721-7730.

(31) Fukuta, S.; Seo, J.; Lee, H.; Kim, H.; Kim, Y.; Ree, M.; Higashihara, T. 2,2'-Bis(1,3,4-Thiadiazole)-Based $\pi$-Conjugated Copolymers for Organic Photovoltaics with Exceeding $8 \%$ and Its Molecular Weight Dependence of Device Performance. Macromolecules 2017, 50, 891-899.

(32) Wang, Y.; Cui, H.; Zhu, M.; Qiu, F.; Peng, J.; Lin, Z. Tailoring Phase Transition in Poly(3-Hexylselenophene) Thin Films and Correlating Their Crystalline Polymorphs with Charge Transport Properties for Organic Field-Effect Transistors. Macromolecules 2017, 50, 9674-9682.

(33) Iovu, M. C.; Sheina, E. E.; Gil, R. R.; McCullough, R. D. Experimental Evidence for the Quasi-"living" Nature of the Grignard Metathesis Method for the Synthesis of Regioregular Poly(3Alkylthiophenes). Macromolecules 2005, 38, 8649-8656.

(34) Miyakoshi, R.; Yokoyama, A.; Yokozawa, T. Catalyst-Transfer Polycondensation. Mechanism of Ni-Catalyzed Chain-Growth Polymerization Leading to Well-Defined Poly(3-Hexylthiophene). J. Am. Chem. Soc. 2005, 127, 17542-17547.

(35) Sato, M. A.; Tanaka, S.; Kaeriyama, K. Electrochemical Preparation of Highly Anode-Active Poly(3-Phenylthiophene). J. Chem. Soc., Chem. Commun. 1987, 1725-1726.

(36) Pei, Q.; Jarvinen, H.; Osterholm, J. E.; Inganaes, O.; Laakso, J. Poly[3-(4-Octylphenyl)Thiophene], a New Processible Conducting Polymer. Macromolecules 1992, 25, 4297-4301.

(37) Ohshimizu, K.; Takahashi, A.; Rho, Y.; Higashihara, T.; Ree, M.; Ueda, M. Synthesis and Characterization of Polythiophenes Bearing Aromatic Groups at the 3-Position. Macromolecules 201 1, 44, 719-727. 
(38) Wang, Y.; Heck, B.; Schiefer, D.; Agumba, J. O.; Sommer, M.; Wen, T.; Reiter, G. Anisotropic Photophysical Properties of Highly Aligned Crystalline Structures of a Bulky Substituted Poly(Thiophene). ACS Macro Lett. 2014, 3, 881-885.

(39) Haba, O.; Hayakawa, T.; Ueda, M.; Kawaguchi, H.; Kawazoe, T. Synthesis of a Regioregular Head-to-Tail Poly(3-Alkylphenylthiophene) by Oxidative Coupling Using $\mathrm{VO}(\mathrm{Acac}) 2$. React. Funct. Polym. 1998, 37, 163-168.

(40) Aasmundtveit, K. E.; Samuelsen, E. J.; Mammo, W.; Svensson, M.; Andersson, M. R.; Pettersson, L. A. A.; Inganäs, O. Structural Ordering in Phenyl-Substituted Polythiophenes. Macromolecules 2000, 33, 5481-5489.

(41) Hou, J.; Yang, C.; Li, Y. Synthesis of Regioregular Side-Chain Conjugated Polythiophene and Its Application in Photovoltaic Solar Cells. Synth. Met. 2005, 153, 93-96.

(42) Hou, J.; Yang, C.; He, C.; Li, Y. Poly[3-(5-Octyl-ThienyleneVinyl)-Thiophene]: A Side-Chain Conjugated Polymer with Very Broad Absorption Band. Chem. Commun. 2006, 871-873.

(43) Hou, J.; Tan, Z.; Yan, Y.; He, Y.; Yang, C.; Li, Y. Synthesis and Photovoltaic Properties of Two-Dimensional Conjugated Polythiophenes with Bi(Thienylenevinylene) Side Chains. J. Am. Chem. Soc. 2006, 128, 4911-4916.

(44) Zhou, E.; Tan, Z.; Huo, L.; He, Y.; Yang, C.; Li, Y. Effect of Branched Conjugation Structure on the Optical, Electrochemical, Hole Mobility, and Photovoltaic Properties of Polythiophenes. J. Phys. Chem. B 2006, 110, 26062-26067.

(45) Holcombe, T. W.; Woo, C. H.; Kavulak, D. F. J.; Thompson, B. C.; Fréchet, J. M. J. All-Polymer Photovoltaic Devices of Poly(3-(4-nOctyl)-Phenylthiophene) from Grignard Metathesis (GRIM) Polymerization. J. Am. Chem. Soc. 2009, 131, 14160-14161.

(46) Takagi, K.; Joo, H.; Yamashita, Y.; Kawagita, E.; Torii, C. Regioselective Grignard Metathesis Reaction of 2,5-Dibromo-3-(6'Hexylpyridine-2'-Yl)Thiophene and Kumada Coupling Polymerization. J. Polym. Sci. A Polym. Chem. 2011, 49, 4013-4020.

(47) Rudge, A.; Davey, J.; Raistrick, I.; Gottesfeld, S.; Ferraris, J. P. Conducting Polymers as Active Materials in Electrochemical Capacitors. J. Power Sources 1994, 47, 89-107.

(48) Guerrero, D. J.; Ren, X.; Ferraris, J. P. Preparation and Characterization of Poly(3-Arylthiophene)S. Chem. Mater. 1994, 6, 1437-1443.

(49) Soudan, P.; Lucas, P.; Breau, L.; Bélanger, D. Electrochemical Modification of Poly(3-(4-Fluorophenyl)Thiophene). Langmuir 2000, $16,4362-4366$.

(50) Naudin, E.; Dabo, P.; Guay, D.; Bélanger, D. X-Ray Photoelectron Spectroscopy Studies of the Electrochemically nDoped State of a Conducting Polymer. Synth. Met. 2002, 132, 71-79.

(51) Shen, L.; Xu, J.; Wei, Z.; Xiao, Q.; Pu, S. Electrosyntheses of Freestanding Poly (3-(4-Fluorophenyl)Thiophene) Films in Boron Trifluoride Diethyl Etherate. Eur. Polym. J. 2005, 41, 1738-1746.

(52) Ferraris, J. P.; Eissa, M. M.; Brotherston, I. D.; Loveday, D. C.; Moxey, A. A. Preparation and Electrochemical Evaluation of Poly (3Phenylthiophene) Derivatives: Potential Materials for Electrochemical Capacitors. J. Electroanal. Chem. 1998, 459, 57-69.

(53) Tsoi, W. C.; Spencer, S. J.; Yang, L.; Ballantyne, A. M.; Nicholson, P. G.; Turnbull, A.; Shard, A. G.; Murphy, C. E.; Bradley, D. D. C.; Nelson, J.; Kim, J. S. Effect of Crystallization on the Electronic Energy Levels and Thin Film Morphology of P3HT:PCBM Blends. Macromolecules 2011, 44, 2944-2952.

(54) Goto, E.; Ochiai, Y.; Lo, C. T.; Koganezawa, T.; Ueda, M.; Higashihara, T. Synthesis of Regioblock Copolythiophene by Negishi Catalyst-Transfer Polycondensation Using ${ }^{t} \mathrm{Bu}_{2} \mathrm{Zn}_{2} \mathrm{LiCl}$. Polym. Chem. 2017, 8, 6143-6149.

(55) Berggren, M.; Gustafsson, G.; Inganäs, O.; Andersson, M. R.; Wennerström, O.; Hjertberg, T. Thermal Control of Near-Infrared and Visible Electroluminescence in Alkyl-Phenyl Substituted Polythiophenes. Appl. Phys. Lett. 1994, 65, 1489-1491.

(56) Fell, H. J.; Samuelsen, E. J.; Andersson, M. R.; Als-Nielsen, J.; Grübel, G.; Mårdalen, J. Structural Aspects of Oriented Poly-
(Octylphenylthiophene) Studied in Bulk and Sub-Micron Layers by X-Ray Diffraction. Synth. Met. 1995, 73, 279-283.

(57) Koeckelberghs, G.; Cornelis, D.; Persoons, A.; Verbiest, T. Regioregular Poly[3-(4-Alkoxyphenyl)Thiophene]s: Evidence for a Two-Step Aggregation Process. Macromol. Rapid Commun. 2006, 27, $1132-1136$. 